\title{
Theory and Practice of Organization of Independent Cognitive Activity of Future Teachers by Means of Information and Communication Technology in Quarantine Conditions in Ukraine
}

\author{
Yaroslav Haleta ${ }^{1 *[0000-0003-0484-529 X]}$, Oleksandr Balanutsa 2 [0000-0002-3470-9486] \\ ${ }^{1}$ Volodymyr Vynnychenko Central Ukrainian State Pedagogical University, Kropyvnytskyi, Ukraine \\ ${ }^{2}$ Ambassador Extraordinary and Plenipotentiary of Ukraine to the State of Kuwait \\ *yaroslavhaleta@ukr.net
}

\begin{abstract}
The paper identifies the conditions that contribute to improving the efficiency of independent work: the availability of the necessary educational and methodological support, the presence of a system for monitoring the quality of independent work; availability of a mobile feedback system (for example, availability of a test task system); availability of computer support. It is shown that the organization of independent work in the information environment is associated with the identification of stages of the process of independent work. There are two main stages of creating and integrating information and learning resources into the traditional learning process. In the course of the research we developed a project to create an information and educational environment - a dynamic system that is a holistic set of educational situations that gradually replace each other. To stimulate the application of knowledge and skills acquired during the course, professionally oriented motivational-stimulating situations were used, which provide for certain steps and sequence of implementation, namely: conducting joint orientation in a personally important subject area for students; identification of problems of interest to students as future teachers; consideration of problems in the context of important for students professional and personal values. An effective version of the organization of students' research work - a "virtual laboratory" - has been developed and tested.
\end{abstract}

Keywords: independent work, information and communication technologies, virtual laboratory, future teacher.

\section{INTRODUCTION}

The education system as a whole and in each individual educational institution can be understood and described as information educational environments, spaces. One of the main features of educational information environments is their systemic nature. Didactic information system is an organizationally organized set of specialists, information resources, educational technologies that carry out the educational process.

In a broad sense, the concept of "environment" is a set of conditions that ensure the development, socialization and education of man. Properly organized learning and information environment allows students to adapt it to themselves, and this is its fundamental difference from the real information environment, in which such adaptation is not always possible. The information environment can change, improve, but this requires targeted action.

New information technologies as a specific learning tool are a means of modeling interaction and organization of joint activities such as "the one who is taught - a group of students", "student - student", "student - teacher".

From the point of view of personality-oriented learning, information technologies open wide opportunities for individualization of educational 
process, introduction of elements of development of creative potential of students in it.

\section{RESEARCH METHODOLOGY}

The methodological basis for the organization of independent activity of students in the informationeducational environment are the following theories and concepts:

- the theory of educational activity, according to which the assimilation of the content of education is carried out in the process of own activity of the one who is taught, which promotes the development of personality;

- the concept of general didactic principles of higher education: scientific, connection of theory with practice, systematicity and consistency in training, consciousness, activity and independence of students in learning, combination of individual search for knowledge with educational work in the team, strength of learning and availability of scientific knowledge.

The use of new information technologies expands the possibilities of activating cognitive activity, improving the set of general logical methods of thinking and a set of special methods of mental activity, as well as increasing the effectiveness of teaching methods.

We have taken into account the research [1-6] on the use of machine learning opportunities during quarantine, in particular the possibilities of social networks.

The practical application of new information technologies can improve or even partially replace in the educational process such classical teaching methods as methods of oral presentation of educational material (lecture, story, explanation, etc.), methods of visual and practical training, methods of consolidation of knowledge, methods of independent work.

\section{RESULTS OF THE RESEARCH}

Within the process of integration of the national education system into the world educational space, independent cognitive activity in the computer environment acquires special significance. In such an environment, independent work is not a supplement to educational work, but a special systemic activity that takes the educational process beyond a single educational institution, not reduced to others, opens access to many new sources of information, equips learners with new tools. its receipt.

Independent cognitive activity in the didactic environment is possible in two forms - as autonomous and as cooperative [7, p. 88].
Successful performance of professional tasks largely depends on the willingness of the specialist to make nonstandard decisions, take responsibility, show independence, mobility. To train such a specialist it is necessary to create appropriate conditions that will form the necessary qualities, skills and abilities of creative activity, ensure the development of internal and external self-organization of the future specialist, actively transforming the attitude to information, ability to build an individual trajectory [8, p. 105].

For this purpose it is important not only to form in students abilities, skills of independent work under the guidance, management of the teacher, but also to teach self-government by own educational activity. This changes the role of the teacher: instead of informative and controlling function, the main function is pedagogical support, support.

Such conditions that contribute to improving the efficiency of independent work include: the availability of the necessary training and methodological support, the availability of a system for monitoring the quality of independent work; availability of a mobile feedback system (for example, availability of a test task system); availability of computer support [9, p. 48].

The organization of independent work in the information environment is associated with the identification of stages of the process of independent work. The stages are as follows:

The first stage is the realization of the need to search for information, to determine search goals. The second stage is the implementation of information retrieval. The third is the processing of information, the choice of storage method. Fourth - the translation of information into knowledge (application in practice).

Features of the organization of independent work in the information environment are connected with a possibility of automation of some stages of educational activity, use of computer programs for the decision of various problems, modeling of various situations, an opportunity to improve historical system of training.

The formation of information and educational environment in any discipline is a fairly long step-by-step process. In that case, if the environment is based on publicly available technologies, their progress forces the teacher to constantly review the instrumental capabilities of the environment and, consequently, its didactic content, methodological solutions, communication functions and the like.

We highlight two main stages of creating and integrating information and learning resources into the 
traditional learning process, which was implemented in 2020 during the lockdown period.

1. The initial stage or stage of "innovation" is usually characterized by the fact that the profile of the traditional course does not change, as do not change in percentage and set components of the course: time spent on classes, independent work, individual tasks, and control over movement of the educational process. But within these limits the teacher finds ways to implement certain elements of the pedagogical process in a new form, using the resources of the information and educational environment. This stage coincides in time with the process of formation and development of information and telecommunication infrastructure of the educational institution and is characterized by limited involvement of students in this infrastructure.

2. The second stage can be called the stage of "pedagogical modernization" - changing the profile of the course. It means more broadly in qualitative and quantitative terms the use of environmental resources in the learning process. The components of the educational process are the implementation of group or individual projects in a computer environment, the transfer of most of the independent work in the telecommunications mode. The level of modernization implies greater independence of the learner and the transition from reproductive exercises performed in a computer environment to an individualized learning process, characterized by a high level of motivation.

In the course of the research we developed a project to create an information and educational environment - a dynamic system that is a holistic set of educational situations that gradually change each other. The educational situation means a system of psychological, pedagogical and didactic conditions and incentives that put a person in front of the need for conscious choice, adjustment and implementation of their own model of learning, ie the implementation of independent learning activities.

The developed information and educational environment implements the following functions:

- prompt delivery of educational information to the student;

- interaction between all participants in the learning process and feedback from the teacher;

- providing individual and group independent work.

Creating an information and educational environment is aimed at:
- creating conditions for students to realize the peculiarities of future professional activity;

- focusing on the development of personal qualities necessary for successful mastery of the future profession;

- determining the level of development of professionally important qualities available to each student, and the construction of individual educational trajectories.

The mechanism of managing the learning process in the environment is based on direct and feedback in the system "Teacher - environment - learner", based on which there are many modifications, for example, "learner - environment - learner - environment - teacher "and the like.

The use of the environment for a separate course included:

- diagnosis of the level of education, the formation of personal professional interests and motives for professional activity;

- selection of level groups on its basis;

- determination of individual educational trajectories, on the basis of which the optimal combination of subject and professional requirements for each student is provided.

The lecture form of study was supplemented by the use of multimedia capabilities of modern technology, which allows you to prepare electronic lectures with audiovisual support of the presented material.

Then the complication of all components of the course is carried out: tasks with life-practical content are introduced, group forms of work that give the opportunity to model situations of cooperation, to explain, control, identify the causes of errors.

At the next stage, motivational-target orientation is associated with the formation of creative skills of the individual in the process of applying knowledge in an unfamiliar situation, expanding the boundaries of cooperation, actualizes the understanding of the need for personal responsibility for the results of their work.

At this stage, stimulating, partially exploratory, controlling, self-controlling methods of teaching are used. The structure of the course involves the widespread use of mutual control, the involvement of future professionals in the self-analysis of their work, setting goals for further work.

To stimulate the application of knowledge and skills acquired during the course, professionally oriented motivational and stimulating situations were used, which 
involve certain steps and sequence of implementation, namely:

1) conducting joint orientation in the subject area that is personally important for students;

2) identification of problems of interest to students as future teachers;

3) consideration of problems in the context of important for students professional and personal values.

Successful work in the information and educational environment is possible only if effective information and knowledge flows are provided, which provide feedback and control.

The connection with the main educational activity and thus increasing the importance of the learning process is achieved through the purposeful use of resources of the information and educational environment in the mode of modeling the future professional activity of students. At the initial stage, the resources of the environment were used to expand the professional horizons and students gain knowledge about the specifics of their professional activities. Reliance on this principle in the learning process in the environment is designed to help build a unique scenario of future professional activity of the student, the continuous improvement of his professional skills. This allows you to identify, explain the informal knowledge that professionals use every day in their practice, make it the subject of study and thus ensure the advanced nature of training.

The next factor in the effectiveness of learning is to take into account the individual differences of learners. The attitude to the student as a subject of educational process in the information-educational environment is connected with the right of choice of each own technology of mastering of knowledge and skills taking into account individual-psychological features of the subject - attention, memory, thinking, type of nervous activity; it is based on the study of individual-typical processes and methods of cognition, on the identification of psychophysiological mechanisms underlying individual-unique ways of mastering new information. The principle of individualization is realized also under the condition of taking into account motivational attitudes, selection of the course structure, at a choice of partners in training.

Finally, learning activities in the information and educational environment will be most effective if it reaches the level of co-creation of all participants in the learning process - those who teach and the teacher, those who learn from each other, those who are taught and members of the network community. When using the principles of personality-oriented developmental education, the information-educational environment appears as a certain organism that is in constant development and improvement, characterized by the personal involvement of all participants in the learning process. Co-creation is manifested in the joint development of the environment, the renewal of its resources, as well as in the disclosure of each other's personal qualities. Active use of the productivity of the environment, which means the realization for those who are taught opportunities not only to acquire language skills, but also to create and present their own products of creative activity, even if not very implemented, is a clear characteristic of the information and educational environment. required by the teacher in the organization of independent work.

To increase the effectiveness of information and communication technologies in the organization of independent work of students, a certain cycle was implemented:

1) video lecture, audio presentation (scribing), educational video;

2) interactive work in the information and educational environment;

3) observation - feedback - evaluation.

Note that the stage of socialization occurs when students share their knowledge, discuss the products made on the forum or on social networks. We encouraged cooperation so that students' independent work could be collective.

One of the forms of organization of scientific student work is student scientific circles. Working in groups helps students to develop and unleash their potential, achieve success and professional growth.

Research activity of students within the limits of our scientific circle allows to reveal as much as possible individuality, creative abilities, readiness for selfrealization of the personality of the future teacher. We have developed and tested an effective version of the organization of group work of students - "virtual laboratory" (Figure 1). According to VV Trukhin, a virtual laboratory "is a software and hardware complex that allows you to conduct experiments without direct contact with the actual installation or in the complet absence of such" [10]. 


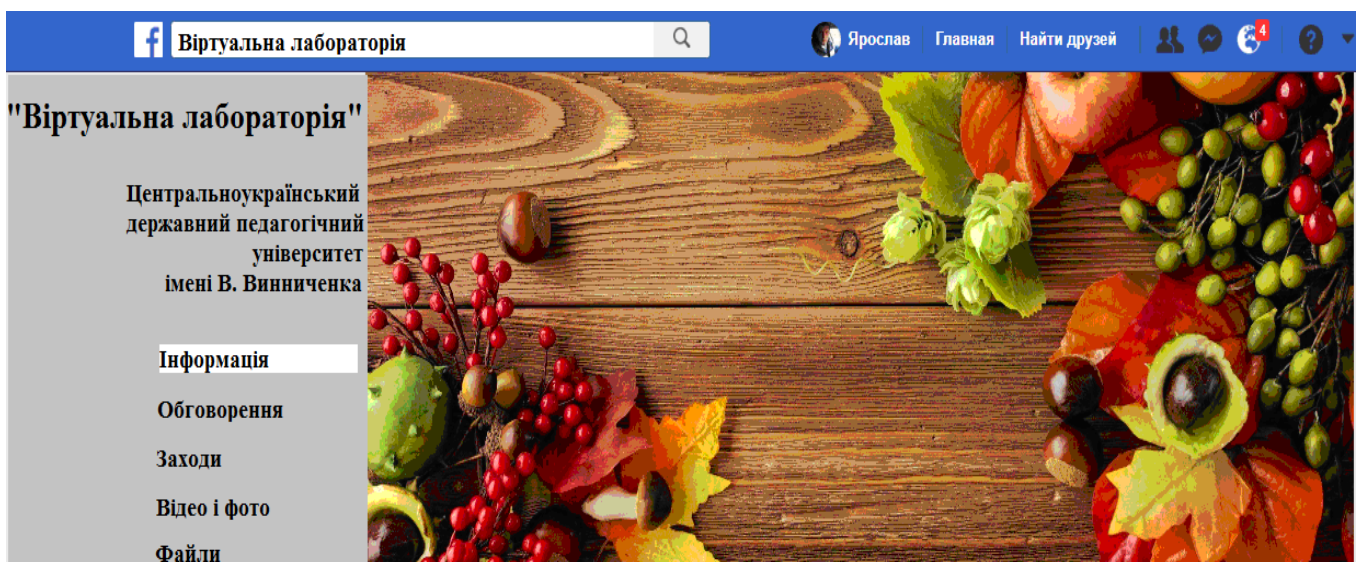

Figure 1 Virtual laboratory

In our case, it is an electronic educational resource made in the form of interactive computer material (tasks, tasks, tests, experiments, etc.). The set of "virtual laboratory" provides computer support for research activities of students. It includes two types of software and hardware:

- laboratory installation with remote access, which includes a real laboratory, software and hardware for plant management and digitization of the received data, as well as means of communication;

- software that allows you to model a variety of psychological and pedagogical processes and situations.

The virtual laboratory provides meaningful blocks related to both the topics of the disciplines (for example, "Child Practical Psychology") and the narrower topics within each discipline (for example, "Diagnosis and development of children's memory").

The capabilities of the "virtual laboratory" allow to organize research in various scientific fields: pedagogy, psychology, sociology, etc., as well as to ensure the interaction of research activities of students and educational institutions of the city.

The material bank of the "virtual laboratory" is formed on three levels of complexity with the possibility of both reproductive learning activities of students and activation of their creative potential.

The complex can be used in different modes: demonstration of tasks using a single computer or projector; individual and group work in a computer class; independent work.

Research skills, abilities and methods of activity that are formed and developed within the framework of "virtual laboratories" include:

- Observation of objects; detection of changes occurring with the object; oral description of the object of observation; written presentation of information about the observed object - the creation of an algorithmic model.

- Identification of individual features in the process of computer modeling and comparison of objects and the results of their transformation.

- The use of a computer model can be accompanied by experimental measurements in different ways.

- Formation of the ability to solve creative tasks at the level of combinations, improvisations: independently draw up an action plan (solution algorithm).

- Acquisition of skills of transfer, search, transformation, storage of information; mastering different ways of presenting information.

- Gaining experience of cooperation in the implementation of group projects.

The main experimental activity of students is carried out at the Department of Pedagogy of Preschool and Primary Education of the Central Ukrainian State Pedagogical University named after Volodymyr Vynnychenko.

We connect the success and efficiency of our proposed ways of organizing independent cognitive activity by means of information and communication technologies with the ability of the future teacher to interact with others in the information and learning environment.

Modern pedagogical education is characterized by the fact that together with knowledge, skills, abilities in the chosen field of activity, the future teacher must have the skills of effective interaction in professional activities, which, on the one hand, are the basis for professional development of the future teacher. on the other hand, act as a result after graduation.

In psychological and pedagogical research, the process of interaction is a relatively new area of theoretical and experimental research, but they open up 
broader perspectives on understanding the problem of personality development.

Ability to interact with the following indicators:

1) the activity of the subjects of interaction, which implies interest, desire to participate and participate in joint activities;

2) the ability to implement a full subjective position: freedom of choice and action, responsibility and independence;

3) the ability to take an active position: to be the object of action;

4) the effectiveness of interaction: the degree of achievement of goals, the effectiveness of achieving results, the optimal ratio of efforts and results, satisfaction of the parties involved, the process and results of joint activities;

5) productivity of interaction: visible results of joint activity, mutual assistance in each other's development.
Analysis of the results of research and experimental work, which studied the impact of a system of measures for the organization of independent cognitive activity by means of information and communication technologies on the criterion of ability to interact, showed that our proposed ways have a high impact factor (Figure 2).

However, we should note that the use of information technology in the structure of conditions gave ambiguous spikes in terms of "activity of the subjects of interaction." We associate this with the short-term impact of information and communication technologies on the motivational sphere.

Of course, information technology provides new opportunities for experience of interaction. We can assume that the criterion we study "ability to interact" is closely related to various phenomena of communication: the search for a reference group, identification with its values and the ability to express themselves in it. Showing special interest in teleconferences for free discussion, students also noted the presence of motives for affiliation, self-realization, cooperation, cognitive and recreational motives.

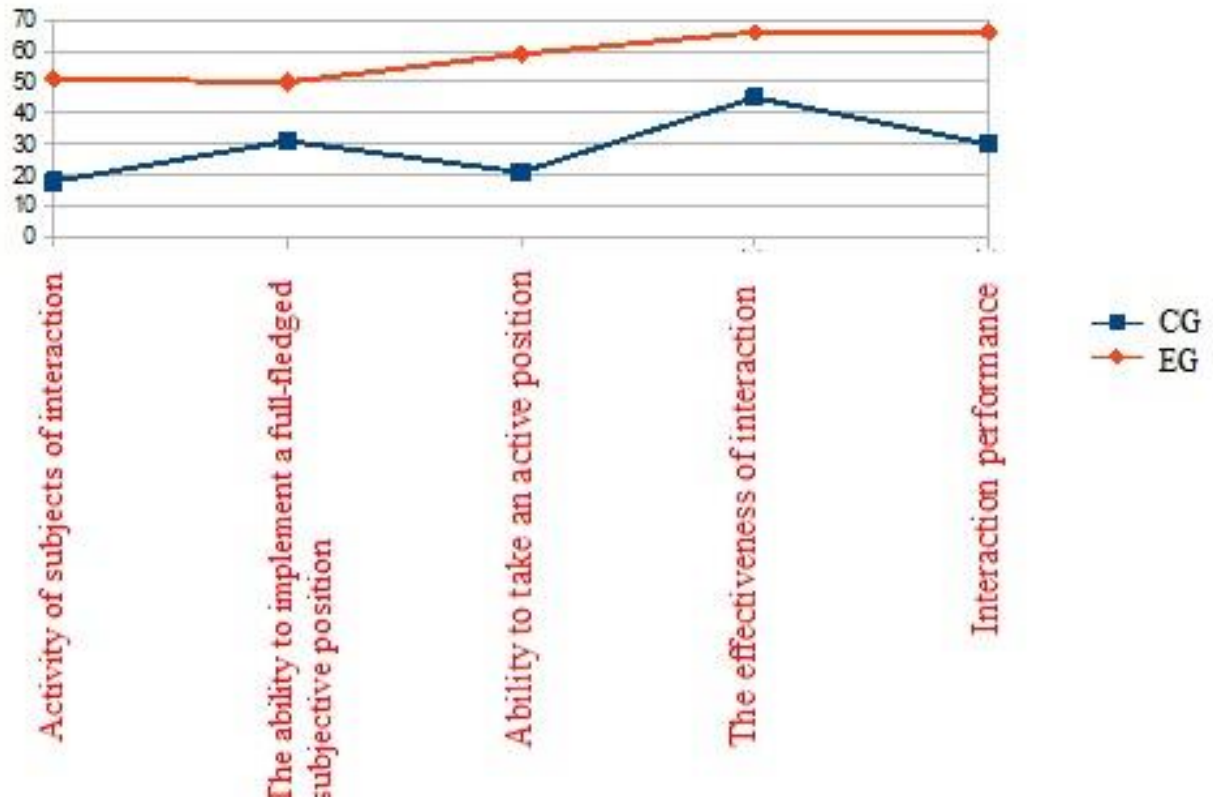

Figure 2 The level of development of social maturity of future teachers by the criterion of "ability to interact" in the control and experimental groups

As conclusions we will note:

- information and communication environment allows for play and improvisation;

- information and communication environment promotes personal development;

- information and communication environment leads to a sense of inclusion in the global information process;
- fascination with the possibilities of information and communication environment leads to the fact that the student forgets about other things.

In students of the experimental group, communicative motivation is observed at the level of $27 \%$. Communicative motivation is the needs, goals, motives, intentions, aspirations that stimulate and support the activity of students' communicative activity, ie as a 
set of psychological reasons explained by the act of communication, interaction, its beginning, direction and activity. Students of the experimental group claim that the information and communication environment allows to overcome the communication deficit that arises in everyday life. The motive of communication is combined with the whole block of motives of social and communicative nature, as well as with the recreational motive.

\section{CONCLUSIONS}

Assessing the consequences of work in the information and communication environment for the individual, the students of the experimental group note the following:

- information and communication environment promotes personal development;

- communication in the information and communication environment leads to the fact that ordinary communication loses its appeal;

- when working in the information and communication environment there is a sense of inclusion in the global information process;

- fascination with the information and communication environment distracts from other things.

We can talk about a special group of students, in whose motivational dispositions over business, professional, cognitive interests are dominated by informal, personal, actually communicative moments. The degree of application of information and communication technologies by a student is measured and evaluated by his ability to acquire knowledge independently, to use already acquired knowledge in initial and practical activities. That is why the purpose of higher education as a basic in a single system of continuing education is to educate students in activity and independence. Self-education can not be properly oriented and can not be successful if the task is not to equip students with a system of skills and abilities of educational work. When organizing independent work of students, the teacher must determine the place and role of information and communication technologies in the system of developing educational process aimed at the creative application of knowledge. The developmental function does not require a simple presentation of knowledge in a particular system, but involves teaching students to think, seek and find answers to questions, gain new knowledge using information and communication technologies.

\section{REFERENCES}

[1] Imrus Salehina, Sadia Tamim Dipa, Iftakhar Mohammad Talhaa, Ibrahim Rayhana and Kanij Fatema Nammi (2021), "Impact on Human Mental Behavior after Pass through a Long Time Home Quarantine Using Machine Learning”, International Journal of Education and Management Engineering, no. 1, pp. 41-50. DOI: 10.5815/ijeme.2021.01.05

[2] Gulara A. Mammadova, Firudin T. Aghayev and Lala A. Zeynalova (2019), "Use of Social Networks for Personalization of Electronic Education", International Journal of Education and Management Engineering, no. 2, pp. 25-33. DOI: 10.5815/ijeme.2019.02.03.

[3] Dr. Dawn Carmichael and Dr. Jacqueline Archibald (2019), "A Data Analysis of the Academic use of Social Media", International Journal Information Technology and Computer Science, no. 5, pp. 1-10. DOI: $10.5815 /$ ijitcs.2019.05.01

[4] Malik Mubasher Hassan, Tabasum Mirza and Mirza Waseem Hussain (2020), “A Critical Review by Teachers on the Online Teaching-Learning during the COVID-19" International Journal of Education and Management Engineering, no. 5, pp. 17-27. DOI: 10.5815/ijeme.2020.05.03

[5] Panchenko, V. Haleta, Y. and Chernenko, O. (2020), "Application of Innovative Smart Technologies of Virtual Reality in Business Education as the Basis of Qualified Professional Preparation of Future Managers", Economics, Finance and Management Review, no. 1, pp. 56-70. DOI: https://doi.org/10.36690/2674-5208-2020-156-70

[6] Kulish, A. Radul, V. Haleta, Y. Filonenko, O. and Karikh, I. (2020), “The Newest Digital Technologies in Education and the Prospects of Their Implementation in Ukraine", Propósitos y Representaciones, no. 8. DOI: http://dx.doi.org/10.20511/pyr2020.v8nSPE2.684

[7] Korotkov, A. M. (2004), "Some features of educational activities in the computer environment", Notices of VGPU, no. 1, pp. 84-92.

[8] Belyaeva, A. P. (2003), "Management of independent work", Higher education in Russia, no. 6, pp. 105-109.

[9] Zhurakovsky, V. Sazonova, Z. Chechetkina, N. Tkacheva, T. and Kurbatov, S. (2003), "Management of independent work: world experience". Higher education in Russia, no. 2, pp. 45-49.

[10] Truhin, A. (2002), "About the use of virtual laboratories in education". Open and distance education, no. 4 (8). pp. 1-2. 